\title{
Sustainable soil and water resources: modelling soil erosion and its impact on the environment
}

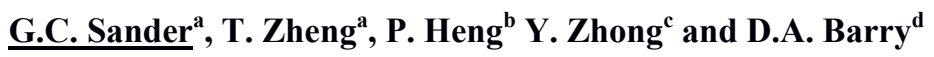 \\ ${ }^{a}$ School of Civil and Building Engineering, Loughborough University, Loughborough, UK, LE11 $3 T U$. \\ Email: g.sander@lboro.ac.uk \\ ${ }^{b}$ Building Research Institute, Housing and Development Board, Singapore, 310480. \\ ${ }^{c}$ Oxford Centre for Industrial and Applied Mathematics, Oxford University, Oxford, UK, OX1 3LB. \\ ${ }^{d}$ Laboratoire de technologie écologique, Institut d'ingénierie de l'environnement, Faculté de l'environnement \\ naturel, architectural et construit (ENAC), Ecole Polytechnique Fédéral de Lausanne (EPFL), Station 2, \\ 1015 Lausanne, Switzerland.
}

\begin{abstract}
With the projected increase in world population to 9 billion by 2050, along with per capita income growth, the demand for land and water resources is going to increase significantly. Conversion of land to intensive agriculture has led to dramatic decreases in plant, animal and insect biodiversity, with approximately $40 \%$ of the world's land surface now covered by croplands and pastures. Intensive agricultural practices cause erosion and lead to transport of soil particles and associated sorbed chemical (fertilizers, pesticides and herbicides) contaminants, which are responsible for significant degradation in the quality of both surface and subsurface water bodies. Soil erosion is an outcome of complex interactions between precipitation, physical transport, topography and conservation management strategies; and there have been many physically based mathematical models developed over the past 20 years that attempt to make predictions of erosion rates as a function of these interactions. These have been applied across scales corresponding to the laboratory, plot, hillslope and watershed with varying degrees of success. Two particular characteristic features of erosion data from both the laboratory and field scale that almost all these models have yet to reproduce reliably are hysteresis in the water discharge versus sediment discharge relationship, and the size distributions of transported sediment. We show that the model of Hairsine and Rose is able to produce the known common types of hysteresis curves, these being clockwise, counter-clockwise, figure 8 (both flow orientations), and that these forms are in keeping with measured data in the literature. Numerical simulations demonstrate that such curves are a consequence of (i) the soil's sediment size distribution and (ii) the existence and evolution of a deposited layer of non-cohesive sediment on top of original un-eroded cohesive soil. It is shown that the initial state of this layer prior to a rainfall event plays a significant role in determining which type of hysteresis loop evolves. An application to published experimental data for flow-driven erosion down a rill is then considered. Excellent agreement between measured and suspended sediment concentrations was found throughout the hysteretic cycle.
\end{abstract}

Keywords: hysteresis, soil erosion modelling, multi-size classes 


\section{INTRODUCTION}

Climate change has focussed the attention of individuals, communities, organisations and governments across the world on the issue of sustainability. Sustainable economic and social development that protects the natural environment and maintains ecosystem biodiversity is an important goal that needs to be achieved to safeguard the quality of life for future generations.

Soil and water are intrinsically fundamental for providing sufficient food to meet the needs of a world population that is expected to exceed 9 billion by 2050 (Powlson et al., 2011). Most significantly though, long-term soil and water sustainability is independent of climate change in the sense that even if climate change does not occur, the problem of maintaining water availability/quality and soil productivity remains. Recent estimates suggest that "since the 1950's irrigated agriculture has expanded globally by $174 \%$, and accounts for approximately $90 \%$ of global freshwater consumption" (Scanlon et al., 2007). Similar figures quoted within the literature concerning agricultural percentages of freshwater usage are those of $85 \%$ by Foley et al. (2005) and greater than $70 \%$ by Sauer et al. (2010). Future water requirements for food production will only increase in order to meet the needs of the projected $50 \%$ population increase by 2050 , by which time it is possible that $75 \%$ of the world's population will not have access to sufficient freshwater (Hightower and Pearce, 2008).

Food production requires land, and agricultural practices have a long record of causing irreversible land degradation, erosion, surface and subsurface water pollution. Available agricultural land amounts to about 4 billion hectares with further estimates of 400 million hectares (10\%) being lost to erosion over the past 50 years (Flanagan, 2001). Economic impacts are felt through a loss of productivity due to the reduction in total soil volume, nutrients and organic matter along with the increasing costs of fertilizer applications to offset the reduced soil quality. Environmental impacts occur through the reduction in the quality of the soil's physical, chemical and biological properties, siltation and increased turbidity of waterways from transported sediment, waterway eutrophication from sediment-sorbed fertilizers and groundwater pollution. The growth of severe hypoxic coastal zones is known to be related directly to river discharges containing high levels of sedimentsorbed nutrients originating from agricultural runoff, and can be found, for example, in the Baltic, Black and East China Seas, and in the Gulf of Mexico (Diaz and Rosenberg 2008, Boesch et al. 2009).

Soil formation rates vary across continents and climatic conditions ranging from $0.3-12 \mathrm{t} / \mathrm{ha} / \mathrm{yr}$ for European mineral soils, $0.004-4 \mathrm{t} / \mathrm{ha} / \mathrm{yr}$ for basaltic parent material in Australia and $7.7 \mathrm{t} / \mathrm{ha} / \mathrm{yr}$ in high rainfall and well-drained watersheds in Japan (Verheijen et al., 2009). While estimates of soil formation rates are approximate, they still provide a reasonable benchmark against which erosion rates can be evaluated. Estimates of average annual soil erosion rates in South America, Africa and Asia are around $30-40 \mathrm{t} / \mathrm{ha} / \mathrm{yr}$ with Australia, Europe and the United States being $17 \mathrm{t} / \mathrm{ha} / \mathrm{yr}$, all of which are far in excess of their soil formation rates (Pimental et al., 1995). Pimental et al. (1995) report that 30\% of USA farmland has been lost to erosion, salinization and water logging over the last 200 years; in 150 years half of Iowa's fertile topsoil and, over the past 100 years, $40 \%$ of soils in the North West have been lost. In addition, they note that $90 \%$ of US cropland is losing soil at a level greater than its formation rate and that over the period of 200 years of US farming, the topsoil has been reduced by one third.

To maintain soil losses at sustainable levels which protect soil resources for future generations, as well as maintaining or even increasing agricultural productivity, requires an ability to estimate soil loss as a function of the complex interactions between precipitation patterns, topography, physical transport processes and conservation management strategies. With this in mind, various physically based mathematical models have been developed over the past 20 years with varying degrees of success (Boardman, 2006). For mechanistic models to provide reliable estimates of sustainable erosion rates, they need to be able to reproduce characteristic features of erosion data obtained from both the laboratory and field scale. Two important features that nearly all models fail to match are transported sediment size distributions and sediment transport hysteresis. As both agricultural chemical and biological pathogens bind preferentially to the clay and silt sized particles, estimating contaminant fluxes to surface water bodies requires knowledge of the size distribution of transported sediment. Sediment transport hysteresis is the term describing different sediment fluxes for the same flow discharge, as is found on the rising and falling limbs of an overland flow hydrograph. Clockwise, anti-clockwise, and two opposing figure 8 orientation loops are known to occur. Here, we present model results that reproduce all four hysteretic loops as well as transported size distributions. We start with a brief overview of the most commonly used erosion models and then proceed to present the results of the hysteresis simulations and comparisons with experimental data. 


\section{SOIL EROSION MODELS}

In most erosion models, the kinematic approximation for overland flow is used. Thus, the one-dimensional mass conservation for water flow and suspended sediment concentration is given by

$$
\frac{\partial h}{\partial t}+\frac{\partial q}{\partial x}=R(t)
$$

and

$$
\frac{\partial(h c)}{\partial t}+\frac{\partial(q c)}{\partial x}=E .
$$

In (1) and (2), $t=$ time $(s), x=$ downslope distance $(m), h=$ flow depth $(m), q=n^{-1} \sqrt{S_{0}} h^{5 / 3}=$ volumetric flow per unit width $\left(\mathrm{m}^{2} \mathrm{~s}^{-1}\right), S_{0}=$ bedslope, $n=$ Mannings' friction coefficient, $R=$ excess rainfall rate $\left(\mathrm{ms}^{-1}\right), c=$ suspended sediment concentration $\left(\mathrm{kg} \mathrm{m}^{-3}\right)$ and $E=$ erosion source and sink terms $\left(\mathrm{kg} \mathrm{m}^{-2} \mathrm{~s}^{-1}\right)$. Typically, $E$ is split into two terms as

$$
E=D_{R}+D_{F},
$$

where $D_{R}=$ rate of soil detachment by raindrop impact and $D_{F}=$ the net rate of soil detachment by the flow, being the difference between the actual flow detachment rate and the deposition of suspended sediment due to gravity. Thus, $D_{F}$ can be either positive or negative depending on whether flow is occurring under net erosion or net depositional conditions. Commonly used erosion models based on (1) to (3) are EUROSEM (Morgan et al., 1998), LISEM (De Roo et al., 1996), KINEROS and KINEROS2 (Smith et al., 1995), WEPP (Flanagan and Nearing, 1995) and the HR (Hairsine and Rose, 1991, 1992).

EUROSEM and LISEM compute soil losses from rainfall detachment through

$$
D_{R}=a_{R} K E \exp (-\xi h),
$$

where $a_{R}$ is a detachability coefficient $\left(\mathrm{kg} \mathrm{J}^{1} \mathrm{~s}^{-1}\right), \mathrm{KE}$ is the rainfall kinetic energy $\left(\mathrm{J} \mathrm{m}^{-2}\right)$ and $\xi$ is a soil texture exponent $\left(m^{-1}\right)$. Both models describe $D_{F}$ by

$$
D_{F}=\frac{\alpha v_{s}}{q}\left(T_{c}-q_{s}\right),
$$

with $q_{s}=q c=$ sediment flux $\left(\mathrm{kg} \mathrm{m}^{-1} \mathrm{~s}^{-1}\right), v_{s}$ is the particle fall velocity $\left(m \mathrm{~s}^{-1}\right), \alpha$ is a flow detachment coefficient and $T_{c}$ is the sediment transport capacity $\left(\mathrm{kg} \mathrm{m}^{-1} \mathrm{~s}^{-1}\right)$. The transport capacity depends on both hydraulic flow properties and soil properties. In the case of EUROSEM and LISEM, $T_{c}$ is calculated as a function of the excess stream power.

KINEROS and KINEROS2 adopt essentially the same relationships as (4) and (5) except that $K E$ is replaced with $P^{2}$ where $P=$ rainfall rate $\left(\mathrm{m} \mathrm{s}^{-1}\right)$ and $T_{c}$ is now calculated as a function of the excess shear stress. In WEPP, contributions to $E$ come from the interrill erosion due to rainfall detachment, and flow-driven erosion within the rills. Interrill erosion is determined through

$$
D_{R}=C_{v} K P^{2},
$$

where $C_{v}$ is a dimensionless cover parameter and $K$ is a soil erodibility parameter $\left(\mathrm{kg} \mathrm{s} \mathrm{m}^{-4}\right)$. While the rate of flow-driven erosion within a rill for $q_{s}>T_{c}$ is still given by (5), for flows where $q_{s}<T_{c}$ it is calculated from a different expression, being

$$
D_{F}=K_{r}\left(\tau-\tau^{*}\right)\left(1-\frac{q_{s}}{T_{c}}\right),
$$

where $K_{r}$ is soil erodibility parameter for the rill $\left(\mathrm{s} \mathrm{m}^{-1}\right), \tau$ is the bed shear stress $(\mathrm{Pa})$ and $\tau^{*}$ is the critical bed shear stress $(\mathrm{Pa})$. WEPP determines the transport capacity by using the formula of Foster and Meyer (1975)

$$
T_{c}=k_{t} \tau^{3 / 2},
$$


with $k_{t}$ being a transport coefficient $\left(\mathrm{m}^{1 / 2} \mathrm{~s}^{2} \mathrm{~kg}^{-1 / 2}\right)$. While EUROSEM and KINEROS use only a single representative size class to characterize a soil, KINEROS2 and WEPP can consider up to five size classes with LISEM taking six. The reason why these models require a transport capacity to be calculated is that they do not consider flow entrainment and sediment deposition as separate mechanisms, but consider instead the net difference between these two. Hence $T_{c}$ is needed in order to differentiate between whether sediment transport is occurring over zones of net erosion $\left(q_{s}<T_{c}\right.$ and $\left.D_{F}>0\right)$ or net deposition $\left(q_{s}>T_{c}\right.$ and $\left.D_{F}<0\right)$.

There are several concerns with basing sediment transport models on the concept of transport capacity. First, erosion is dependent on the soil's particle size distribution, with each size making its own separate contribution to $T_{c}$. Second, it is hysteretic in that different values of $T_{c}$ occur for the same flow rate $q$ on either side of the rising and falling limb of a runoff hydrograph. That $T_{c}$ (for both the total sediment transported as well as that for the individual size classes) is hysteretic was shown in a set of well-controlled flume experiments by Polyakov and Nearing (2003). Thus, particle size class (in practice sediment size classes are used) distribution and hysteresis dependence make it difficult to develop reliable formulas for determining $T_{c}$. While the multi-size class models have developed approximate equations, these are unsatisfactory from a physical point of view as they are effectively a model input. Transport capacity at any given time and spatial location, for any particular flow condition, evolves from the flow itself and is due to the balance between three separate erosion mechanisms, viz., gravity deposition, rainfall and runoff detachment. It is, therefore, an outcome of, and not an input to, the erosion process. In the case of WEPP, different rate equations ((5) and (7)) are even used to describe different aspects of the same physical process and which is therefore physically inconsistent.

The HR (Hairsine-Rose) approach is unique amongst erosion models in that it includes separate rate equations for all three erosion mechanisms, and as such, it does not rely on the concept of transport capacity. This model is also distinctive from those previously presented in other aspects. First, the HR model describes the soil by its particle size probability density function, and is therefore not limited in the number of size classes it considers. When soil particles are in suspension, both the suspension time and transport distance, depend on the particle's settling velocity. With particle size settling velocities varying over many orders of magnitude $\left(10^{-6}-0.1 \mathrm{~m} \mathrm{~s}^{-1}\right)$, a single effective size class is not representative of the behaviour of eroded soil. As both agricultural chemical (fertilizers, pesticides) and biological (bacteria, viruses) pathogens bind preferentially to the clay and silt sized particles (Morgan and Quinton 2001, Schijven and Hassanizadeh 2000), estimating contaminant fluxes to surface water bodies requires knowledge of the size distribution of transported sediment. Second, the HR model also recognises that eroded soil depositing on the soil surface forms a covering layer that does not possess the same cohesive strength of the original soil. Due to the sizeselective nature of the deposition process, the distribution of sediment in the covering layer is different to the original soil material. The HR model therefore has a separate mass conservation equation for the evolution of the size distribution in the deposited layer throughout the erosion event. Experimental work by Heilig et al. (2001) shows how this deposited layer develops through time.

Figure 1 shows the conceptual layout of the HR model. Here, $i$ is the sediment size class, $d_{i}\left(\mathrm{~kg} \mathrm{~m}^{-2} \mathrm{~s}^{-1}\right)$ is the deposition rate, $e_{i}$ and $e_{d i}\left(\mathrm{~kg} \mathrm{~m}^{-2} \mathrm{~s}^{-1}\right)$ are the rainfall detachment rates from the original un-eroded soil and deposited layer, respectively, $r_{i}$ and $r_{r i}\left(\mathrm{~kg} \mathrm{~m}^{-2} \mathrm{~s}^{-1}\right)$ are the sediment entrainment rates (flow-driven detachment) from the un-eroded soil and deposited layer, respectively. Last, $c_{i}\left(\mathrm{~kg} \mathrm{~m}^{-3}\right)$ and $\mathrm{m}_{i}\left(\mathrm{~kg} \mathrm{~m}^{-2}\right)$ are the suspended sediment concentration and mass of deposited sediment, respectively. Mass conservation for the HR model is therefore given by

$$
\frac{\partial\left(h c_{i}\right)}{\partial t}+\frac{\partial\left(q c_{i}\right)}{\partial x}=e_{i}+e_{d i}+r_{i}+r_{r i}-d_{i}, i=1,2, \ldots, I
$$

and

$$
\frac{\partial m_{i}}{\partial t}=d_{i}-r_{r i}, i=1,2, \ldots, I,
$$

where $I$ is the total (arbitrary) number of size classes used to subdivide the particle size distribution. The particular functional forms used for the erosion terms are 


$$
\begin{aligned}
& e_{i}=a(h) p_{i} P(1-H), \quad e_{d i}=a_{d}(h) P H \frac{m_{i}}{m_{t}}, r_{i}=\frac{F}{J} p_{i}(1-H)\left(\Omega-\Omega_{c r}\right), \quad d_{i}=v_{i} c_{i}, \\
& r_{r i}=\frac{F}{g h} \frac{\rho_{s}}{\rho_{s}-\rho} H\left(\Omega-\Omega_{c r}\right) \frac{m_{i}}{m_{t}}, \quad H=\min \left(1, \frac{m_{t}}{m_{t}^{*}}\right), \frac{a}{a_{o}}=\frac{a_{d}}{a_{d o}}= \begin{cases}1 & h \leq \bar{h} \\
(\bar{h} / h)^{\delta} & h>\bar{h}\end{cases}
\end{aligned}
$$

in which $a$ and $a_{d}\left(\mathrm{~kg} \mathrm{~m}^{-3}\right)$ are flow depth-dependent soil detachability coefficients for the original soil and deposited layer respectively, $\bar{h}(m)$ is the threshold depth for detachment rates, $\delta$ is a soil characteristic parameter, $p_{i}\left(0<p_{i} \leq 1\right.$ and $\left.\Sigma p_{i}=1\right)$ is the proportion of sediment in size class $i$ of the original un-eroded soil, $H(0 \leq H \leq$ $1)$ is the protection factor

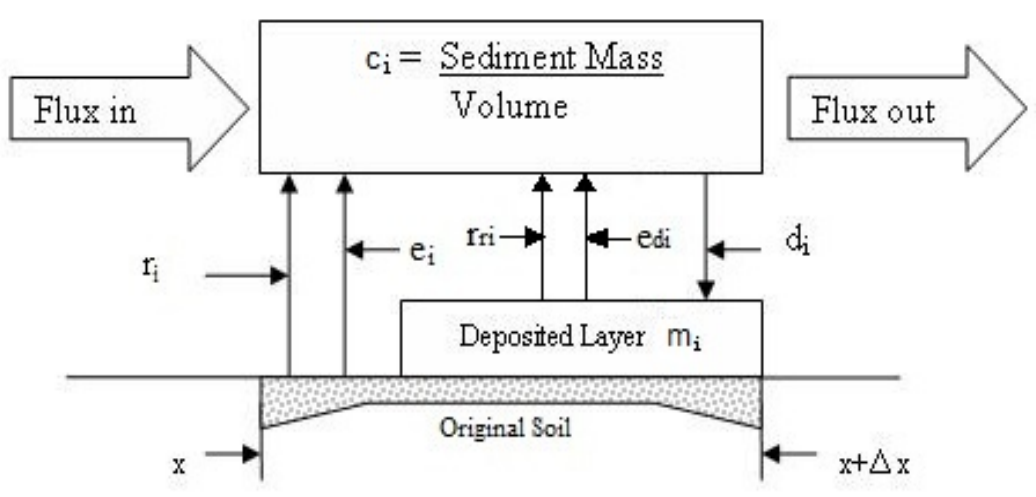
provided by the deposited layer, $F$ is the fraction of excess stream power effective in entrainment, $J$ $\left(J \mathrm{~kg}^{-1}\right)$ is the specific energy of entrainment, $\rho$

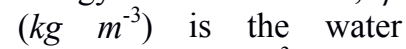
density, $\rho_{s}\left(\mathrm{~kg} \mathrm{~m}^{-3}\right)$ is the particle density, $g\left(m^{-2}\right)$ is the magnitude of gravitational acceleration, $\Omega=\rho g S_{0} q\left(W m^{-2}\right)$ is the stream power with $\Omega_{c r}$ the critical threshold stream power below which $r_{i}$ and $r_{r i}$ are zero, $v_{i}\left(m s^{-1}\right)$ are the fall velocities for each size class and $m_{t}{ }^{*}$ is the mass per unit area of deposited sediment required to protect the original soil from further erosion, $m_{t}=\Sigma m_{i}$. The total suspended sediment concentration, $c$, is found by summing across all $c_{i}$.

\section{HYSTERESIS AND SEDIMENT TRANSPORT}

Hysteresis in sediment transport has been known for some time especially within the fluvial geomorphology community. Plots of suspended sediment concentration versus river discharge have shown that the concentrations on the rising limb of the river discharge hydrograph were different to those on the falling limb (Klein 1984, Williams 1989, Seeger et al. 2004, Smith and Dragovich 2009, Eder et al. 2010). Experimental data has shown that there are three common shapes of the hysteresis loops encompassing (i) clockwise, (ii) counter clockwise and (iii) figure 8, though analyses from Williams (1989) suggest it is possible to obtain loops which are (iv) single valued or (v) single valued plus a loop. It has been suggested that the shape of these loops can be used to identify the different processes of runoff and sediment transport (Seeger et al., 2004) and the sediment source area (Klein, 1984). We present simulations carried out for flow conditions that are straightforward to establish within a laboratory flume. The flume's bed is impervious, and it is filled with saturated soil over which there is a very small overland flow. Thus, at $t=0, h=h_{0}$ and $c_{i}=0$. Since the flume is saturated and impervious there is no infiltration, $R=P$ and runoff starts at $t=0$. A physically sensible single peak time-dependent excess rainfall rate for generating a runoff hydrograph with both rising and falling limbs is

$$
R(t)=P(t)=R_{0} \exp (-b t)[1-\exp (-b t)],
$$




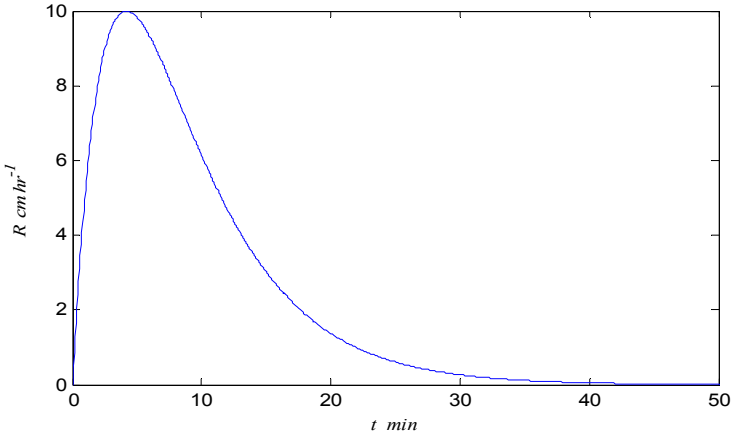

Figure 2. Excess rainfall rate $R(t)$ from (12). $R_{0}=40 \mathrm{~cm} \mathrm{hr}^{-1}$, $b=10 h r^{-1}$.
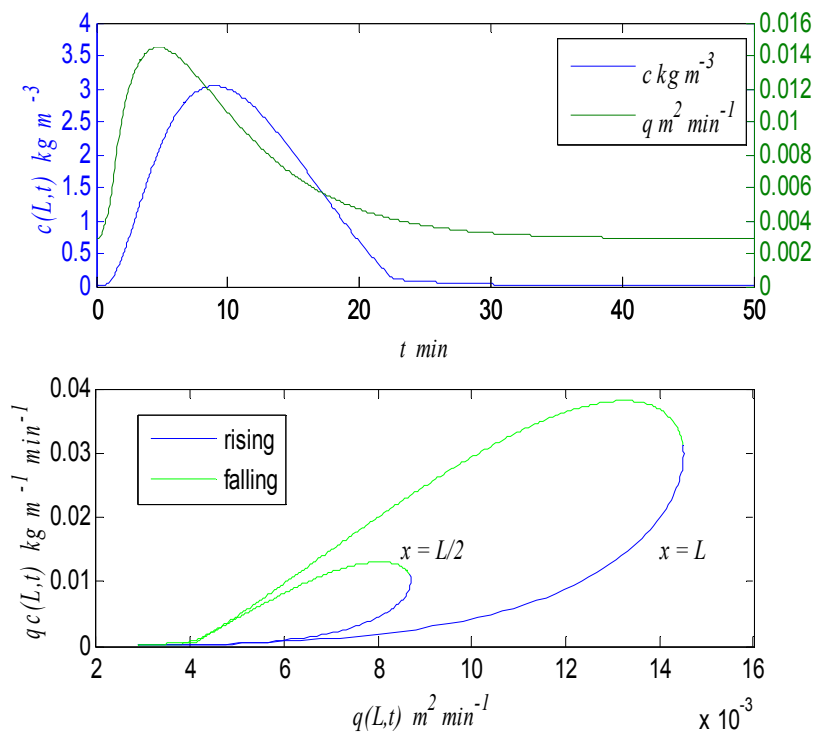

Figure 3. Total suspended sediment concentration and water discharge exiting the flume (top), and counter clockwise loop (bottom). Flume length $L=7 \mathrm{~m}$. and shown in Figure 2. The remaining boundary conditions are taken as $x=0, h=$ $h_{0}$ and $c_{i}=0$. The final initial condition for $m_{i}$ is specified below in discussion with the different hysteretic classes. The full system of equations, given by (1) and (9) to (11), was solved using the method of lines.

\subsection{Sediment-discharge hysteresis loops}

\section{Counter clockwise loop}

Counter clockwise hysteresis loops are known to arise when the peak water discharge occurs before the peak sediment concentration (Williams, 1989). These types of loops occur when the source of eroded sediment is distributed uniformly over the entire catchment, and when the sediment supply is not easily eroded (Seeger et al. 2004, Oeurng et al. 2010). To simulate these conditions for flow in a flume, it is assumed that at the start of the experiment no deposited layer has developed and only cohesive soil is in the flume. The remaining initial condition is therefore given by $t=0, m_{i}=0$.

The top plot in Figure 3 shows the variation of the total suspended sediment concentration, $c$, and water flux, $q$, as a function of time at the end of the flume. The lower graph is a plot of the sediment flux $q c$ as a function of the discharge $q$ at two spatial locations. While the lower plot shows counter clockwise hysteretic loops at both locations in the flume, similar loops occur for all $x$. The size of the loop reduces for decreasing $x$ due to $q$ being predominantly an increasing function of $x$. The appearance of a discontinuity in the slope of $c$ at around $22 \mathrm{~min}$ is due to the stream power falling below its threshold value whereupon the entrainment processes stop contributing to $c$. That $c$ has a greater value for the same discharge on the falling limb as opposed to the rising limb of the hydrograph occurs because on the rising limb sediment is being transported under net erosion conditions. Hence, a significant amount of the flow energy and rainfall impact is being used to erode cohesive soil. On the falling limb, net deposition conditions occur and there is a well-developed deposited layer of noncohesive soil that is far easier to erode and transport than the cohesive soil. Hence, the sediment flux is larger on the falling limb and a counter-clockwise loop is obtained.

\section{Clockwise loop}

Clockwise loops most commonly occur when the sediment peak occurs before the water discharge peak and when there is a source of easily erodible sediment which can be rapidly depleted (Williams, 1989). This suggests that the flume simulation should begin with a fully developed deposited layer (i.e., $H=1)$ of noncohesive sediment, which would typically arise from a previous erosion event. Let us assume that this layer is comprised of size classes in proportion to the original soil, then the initial condition for $m_{i}$ is $t=0, m_{i}=p_{i} m_{t}{ }^{*}$. The corresponding numerical results are presented in Figure 4 where clockwise hysteresis loops (lower graph) are found for all $x$. As also found experimentally, the peak in $c(L, t)$ occurs before the discharge peak. 

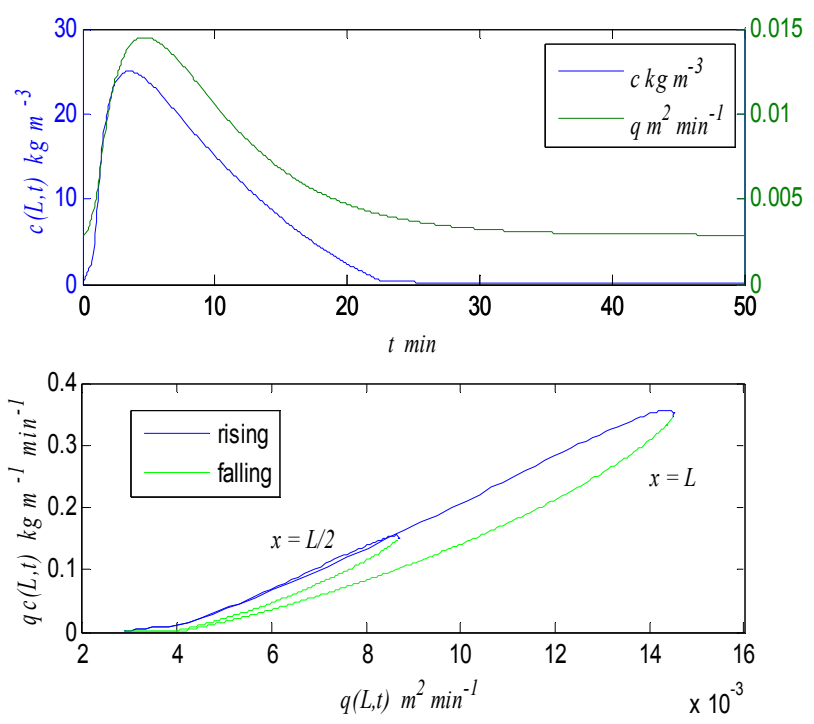

Figure 4. Clockwise loop, $L=7 \mathrm{~m}$
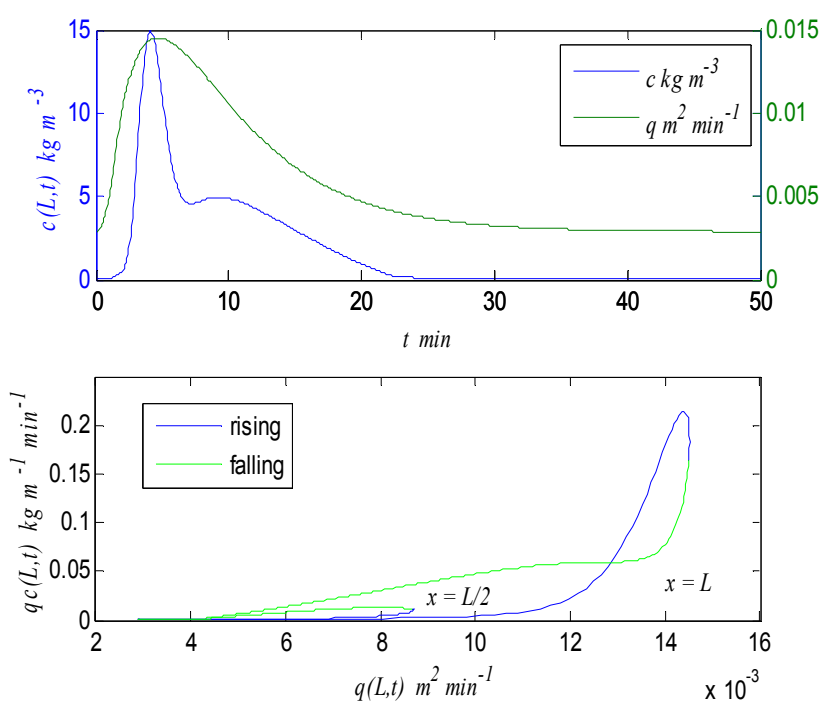

Figure 5. Figure 8 loop.
The initial non-cohesive deposited layer provides an easily erodible source of sediment that is removed on the rising limb of the hydrograph. As this layer is depleted, more of the original cohesive soil, which is less erodible than the deposited layer, is exposed. Next, as the event evolves, the deposited layer becomes increasingly dominated by the larger sediment size classes. Consequently, during the falling limb of the hydrograph for the same discharge, lower sediment concentrations are observed since now cohesive soil and larger, deposited particles are being eroded. Thus, $c$ is much higher on the hydrograph's rising limb in comparison to its value on the falling limb for the same discharge.

\section{Figure 8 loops}

The hysteresis loops in Figures 3 and 4 evolved from counter clockwise to clockwise when the initial conditions changed from having no deposited layer to a fully developed deposited layer. This suggests that a figure 8 loop results from an intermediate initial state. Figures 5 and 6 demonstrate figure 8 loops with opposing flow orientations. Figure 5 arises from having $m_{i}=0$ throughout the solution domain except for a thin strip of deposited soil in $6<x<6.5 \mathrm{~m}$ in which $m_{i}=p_{i} m_{t}{ }^{*}$. Figure 6 is obtained by reversing the previous initial conditions. Taking Figure 5; for $t<3$ min both $c(L, t)$ and $q c(L, t)$ respond similarly to Figure 3 since they have the same initial conditions for $x>6.5$ $m$. By $t=3 \mathrm{~min}$ though, some of the sediment from the easily erodible strip in 6 $<x<6.5 m$ has reached the end of the flume. Then, both $c$ and $q c$ at the flume exit increase rapidly for a few minutes. By

the end of this period a significant percentage of the finer particles that were originally in this strip, and which make the greatest contribution to $c$, have been transported from the flume, and so $c$ and $q c$ start to decline quickly. Rather than $q c$ continuing to decline on the falling limb and forming a clockwise loop, it levels off and crosses the rising hysteresis limb. This is because the easily erodible strip has not been fully depleted, and material from this strip is still making its way out of the flume.

The results in Figure 6 are essentially the reverse of those in Figure 5. That is, the discharge initially behaves as in the case of Figure 4 and $q c$ at the flume exit rises quickly. This is followed by a sudden dip due to the rapid depletion of fine particles in the non-cohesive sediment in the region $6.5<x<7 \mathrm{~m}$ and the lack of sufficient fine replacement sediment being transported from the upstream cohesive region $6<x<6.5 \mathrm{~m}$. At around 5 min some of the initial loose non-cohesive sediment from $x<6 m$ has reached $x=L$ and both $c$ and $q c$ increase slightly before declining at a slower rate than previously, due to the outflow of loose sediment initially located from $x<6 \mathrm{~m}$. This results in $q c$ crossing the rising limb and forming a figure 8 loop of opposite orientation to that of Figure 5. Interestingly, both Figures 5 and 6 closely mimic Figures $6 \mathrm{~d}$ (Oeurng et al., 2010) and 6c (Eder et al., 2010) respectively obtained from catchments in France and Austria. On a final point we note that due to spatially varying initial conditions for $m_{i}$, the hysteresis loops in both Figures 5 and 6 at $x=L / 2$ are quite different to those at $x=L$. So far only preliminary investigations have been carried 
on the effect of particle size distributions. Simulations using a single particle size for the same initial conditions of Figures 5 and 6 resulted in narrow clockwise hysteresis loops. Obviously much further work is required to form definitive conclusions but these preliminary runs do demonstrate the importance of size distributions on hysteresis.
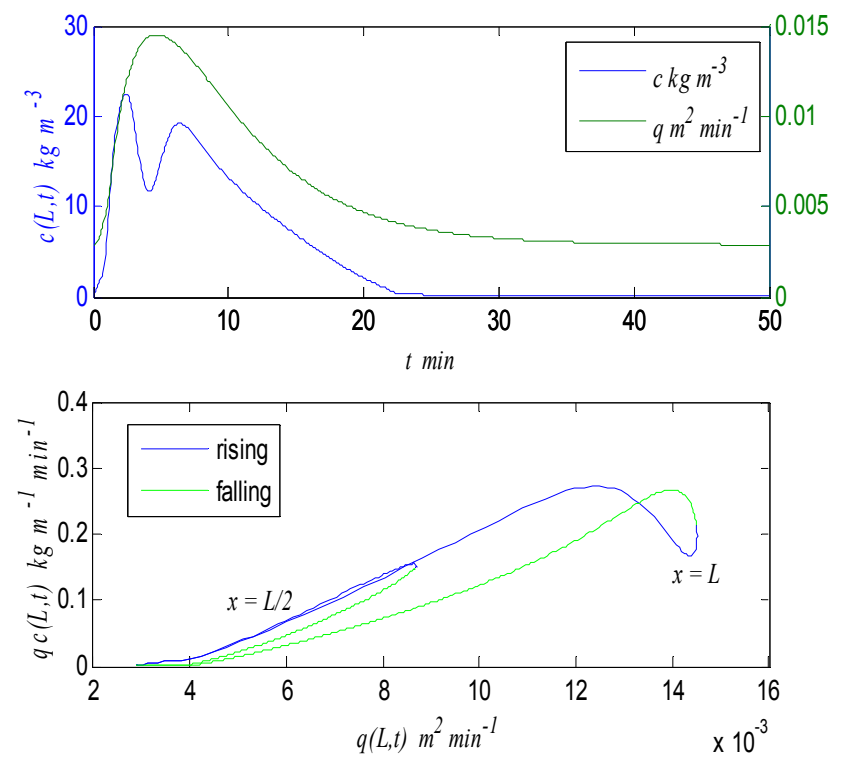

Figure 6. Figure 8 loop with reverse orientation

Catchment studies in the literature have shown that the types of hysteresis loops found depend on initial soil moisture, previous precipitation events, total rainfall rate, maximum rainfall intensity and variability in rainfall intensity (Seeger et al. 2004, Elder et al. 2010). Clearly none of this is surprising as these factors affect the initiation of surface runoff, time to peak discharge, the episodic movement and deposition of sediment throughout the catchment (i.e., deposited layer) and the rate of its depletion. To some extent we have tried to simulate these effects through imposing different initial conditions on $m_{i}$, i.e., $m_{i}=0$ and $p_{i} m_{t}{ }^{*}$ at $t$ $=0$ for all $x$ to represent surface conditions arising from both long and short periods between erosion events. Episodic rainfall events of short duration or events with multiple peaks will result in non-homogeneous distributions of deposited sediment for the next rainfall event. Such circumstances point to a further advantage of the HR formulation in that the deposited layer allows for varying initial surface states to be prescribed prior to any erosion event.

\section{EXPERIMENTAL VALIDATION OF HR MODEL AND HYSTERESIS}

Polyakov and Nearing (2003) performed two sets of experiments that showed that the transport capacity in a rill was not unique for a given soil type, flow rate, and slope. A Carmi loam soil was used in the study containing $15 \%$ clay, $58 \%$ silt and $27 \%$ sand. One set of experiments considered steady state flow along an 8 $m$ rill under both net erosion and net deposition conditions with a constant discharge and depth but with different sediment concentration boundary conditions. Sander et al. (2007) subsequently showed that the HR model was able to predict the hysteretic size distribution of eroded particles for both experiments. The second set of experiments of Polyakov and Nearing (2003) used a 2- $m$ rill and were concerned with the time variation of eroded sediment for an inflow condition at $x=0$ that cycled every 15 min between net erosion (zero inflow concentration) and net deposition (high inflow concentration) states. The experimental results for a steady flow rate of $61 \mathrm{~min}^{-1}$ and the inflow boundary conditions of ( $t$ in $\min$ )

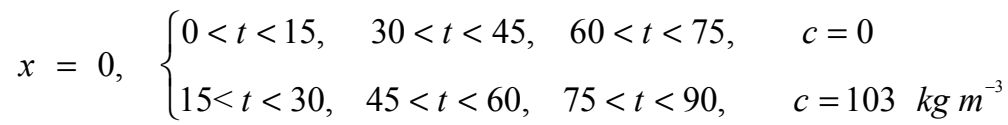

are presented in Figure 7. Parameter values used in the HR model are mostly taken from Sander et al. (2007). Overall, excellent agreement with the experimental data is found, with both the rate of rise and decline in $c$ following the switching of the boundary conditions being captured by the HR model. The HR model also shows that it is capable of reproducing the hysteresis in the transport capacity between the two flow regimes. The results of Figure 7 in combination with those of Sander et al. (2007) add to the existing experimental validations of the HR model. In Figure 8 the spatial distribution of $m_{t}=\Sigma m_{i}$ at $t=90 \mathrm{~min}$ is presented. Similar looking distributions were found at the end of each depositional period at 30 and $60 \mathrm{~min}$. The noticeable feature is the rapid rise in $m_{t}$ to $1032 \mathrm{~kg} \mathrm{~m}^{-2}$ near $x=0$. This can be converted to a change in bed elevation given by $m_{t} /(1-\phi) \rho_{\mathrm{s}}$, where $\phi$ is the porosity of the deposited sediment. Taking $\rho_{\mathrm{s}}=2000 \mathrm{~kg} \mathrm{~m}^{-3}$ and typical values of $\phi(0.4$ to 0.6$)$, gives the change in the bed elevation near $x=0$ as between 86 and 129 $\mathrm{cm}$ which is clearly not physically realistic. The initial physical inconsistency emanates from the first net 
Sander et al., Soil erosion: modelling and its impact on the environment

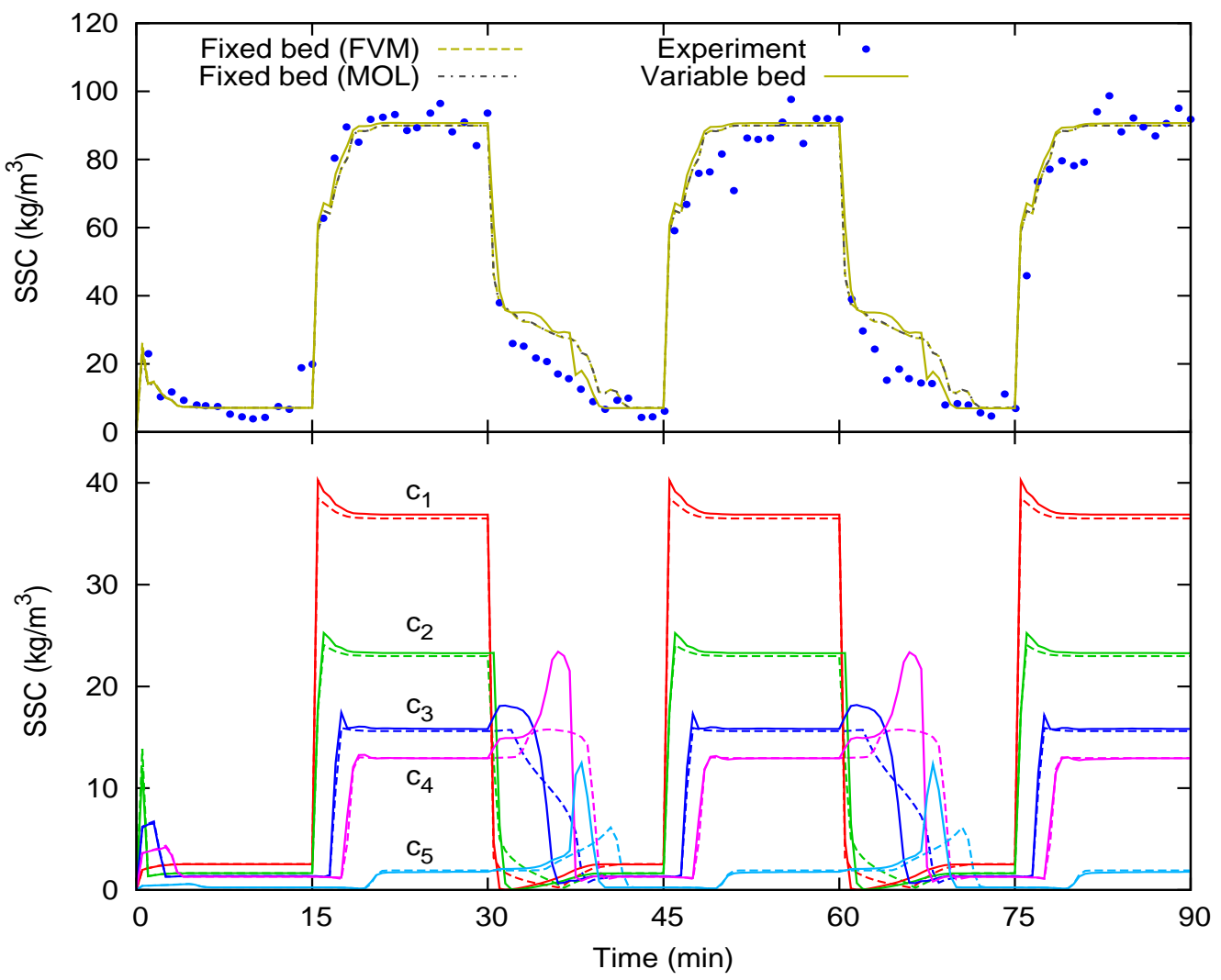

Figure 7. Measured (dots, data from Polyakov and Nearing, 2003)) and predicted (solid and dotted lines) outflowing suspended sediment concentrations at $L=2 \mathrm{~m}$. The upper graph shows model results from both fixed bed and variable bed computations for $c$. The lower graph compares the fixed and variable bed model results for the $c_{i}$ 's. $\mathrm{FVM}=$ finite volume method, $\mathrm{MOL}=$ method of lines.

deposition period occurring for $15<t<30$ min where significant amounts of sediment are deposited near $x=$ 0 . The data in Table 2 of Polyakov and Nearing (2003) result in a

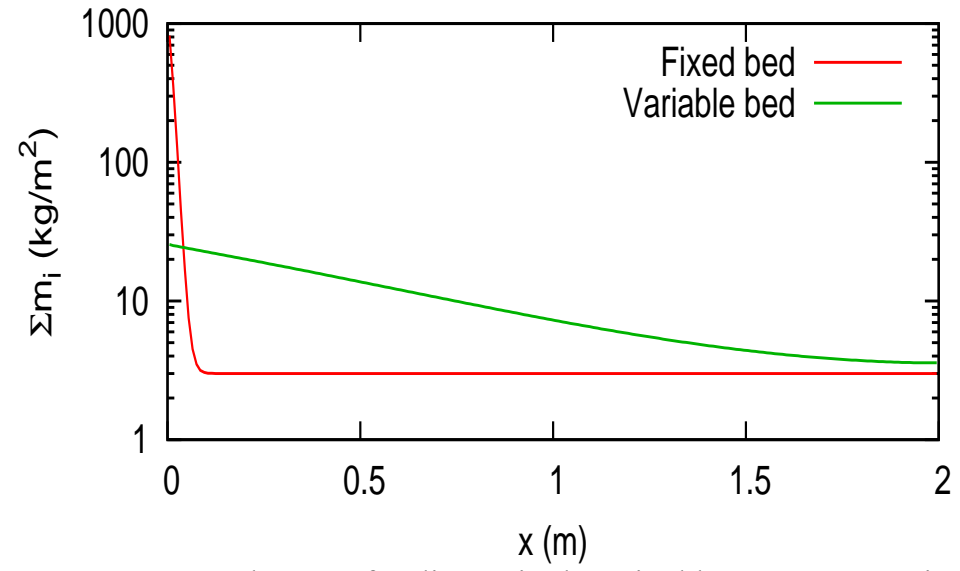

Figure 8. Total mass of sediment in deposited layer at $t=90 \mathrm{~min}$ Froude number $(F r)$ at $x=2 m$ of 1.1 , indicating supercritical flow down the rill. Linear stability analysis of flow and bedform evolution in rivers (Fowler, 1997) shows that, for $F r>1$, there is a strong coupling between the flow velocity, flow depth and the bed morphology resulting in the formation of both dunes and antidunes. Previously published rill results from both experimental data (Nearing et al. 1997, Giménez and Govers 2001) and numerical modelling (Lei et al., 1998) have shown the importance of bed evolution on transport processes for Froude numbers near unity. Thus, the physical inconsistency in Figure 8 is likely due to neglecting the impact of evolving bed morphology on flow hydraulics, which is now addressed. 


\subsection{Including morphological evolution}

When morphological feedback is significant, instead of the simple hydrograph used above it is necessary to solve the full St Venant equations. In addition, mass conservation for the bed height $z$ is required for which an Exner style equation is used. The flow and bedform evolution model adopted is (Cao et al., 2002)

$$
\begin{aligned}
& \frac{\partial h}{\partial t}+\frac{\partial q}{\partial x}=-\frac{\partial z}{\partial t} \\
& \frac{\partial q}{\partial t}+\frac{\partial}{\partial x}\left(\frac{q^{2}}{h}+\frac{g h^{2}}{2}\right)=g h\left(-\frac{\partial z}{\partial x}-S_{f}\right)
\end{aligned}
$$

and

$$
\rho_{s}(1-\phi) \frac{\partial z}{\partial t}=\sum_{i=1}^{I} d_{i}-r_{r i}-r_{i}
$$

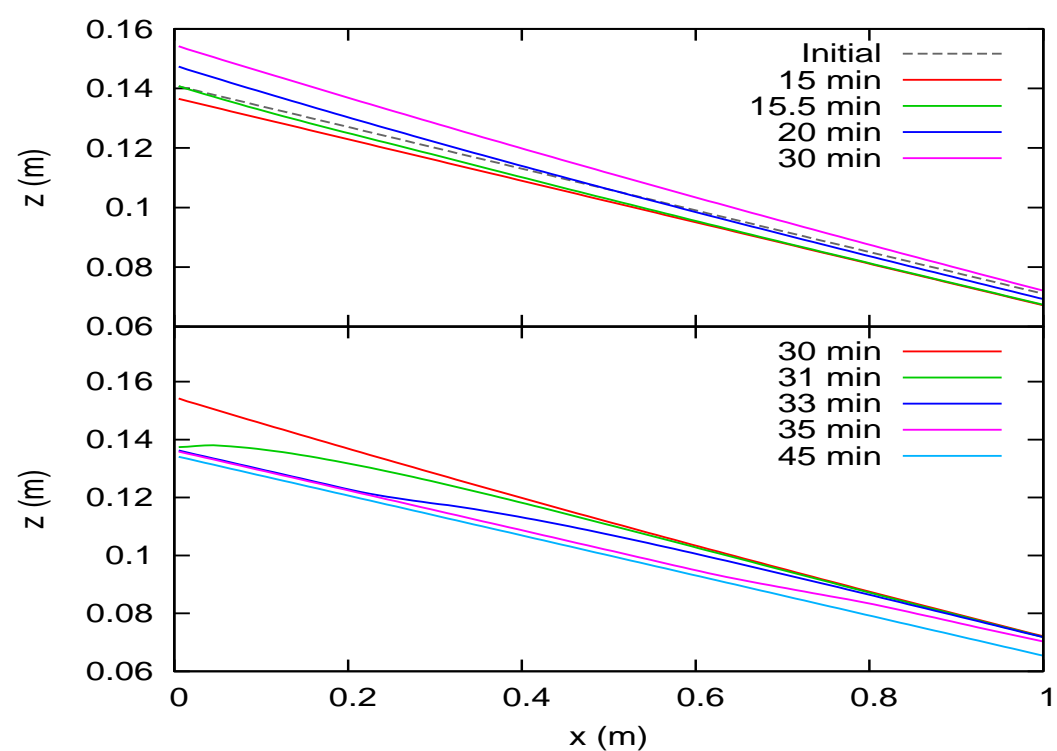

Figure 9. Bed elevations during subsequent deposition and erosion periods. where $S_{f}$ is the friction slope given by Mannings' equation as $S_{f}=n^{2} q^{2} / h^{10 / 3}$. Note that a vertical coordinate system is used in the above equations, i.e., $z$ is the vertical height above datum, $x$ is horizontal distance $h$ is the vertical depth of flow and $q$ is the horizontal flux. This model was solved using the finite volume method of Heng et al. (2009). Figures 7-9 show the results of the HR model when bed evolution is included. These demonstrate that through including the effect of bed evolution on both the flow hydraulics and erosion processes, physically realistic changes in bed height are now found

(Figures 8 and 9) while good agreement with suspended sediment concentrations are maintained (Figure 7).

As boundary conditions are cycled between net erosion and net deposition there are rapid and substantial changes in the local bed slopes throughout the length of the rill. This results not only in considerable variation of flow velocity and discharge with distance, but also in the total sediment load transported down the rill. In particular, at the entry to the rill $(x=0)$, there will be a region where the greatest spatial and temporal changes in bed morphology occur, either as a result of increased erosion during the periods of clear water inflow, or from increased deposition during the periods of sediment-laden inflow. The inclusion of bed evolution counters the build-up of sediment at $x=0$ under net deposition conditions. This is achieved by allowing the local increase in bedslope to feed back into the momentum equation resulting in a locally increased flow velocity, fluid flux and streampower. Consequently, there is a greater re-entrainment rate and therefore greater sediment transport at the boundary that stops the excessive build-up of deposited sediment.

\section{CONCLUSIONS}

The continual loss of both soil volume and soil fertility from agricultural land due to soil erosion seriously threatens the long term sustainability of global food production. Erosion is known to be responsible for groundwater pollution, eutrophication of inland surface water bodies and the development of severe coastal hypoxic zones as a result of both dissolved and sediment-sorbed fertilizer transport in overland flow. The 
role of soil erosion models is to estimate soil loss as a function of precipitation patterns, topography and physical transport processes such that management strategies can be developed or evaluated for maintaining soil losses at more sustainable levels. Reliable predictions require any model to capture key aspects of experimentally obtained data. In this regard the HR model is superior to other formulations; for not only can it quantify the eroded size distribution of agricultural soils from which better estimates of associated (particle size dependent) contaminant fluxes can be obtained, it can also reproduce known hysteretic discharge loops.

Sediment transport hysteresis occurs from having different sediment fluxes for the same discharge on the rising and falling limb of the overland flow hydrograph. Specifically, clockwise, anti-clockwise and figure 8 loops have been found. We have shown for the first time that the HR model is able to simulate the various hysteretic discharge patterns. More importantly, the model's construction permits a straightforward explanation of the various hysteretic behaviours observed experimentally. Hysteresis occurs due to interactions between variable flow over the soil surface and the differences in cohesion between the original and eroded soil, the latter being more erodible than the former. Our results have demonstrated the importance of the initial state of the soil surface prior to an erosion event. The spatial distribution and particle size composition of previously deposited sediment clearly plays a significant role in determining the erosive response of the land surface. With commonly used formulations, as presented in section 2, being based solely on suspended sediment it is therefore unlikely that they can produce the known types of hysteresis loops. We have also shown that the HR model is capable of reproducing various aspects of experimental data from complex evolving flows resulting from the interaction of hydraulics and bed morphology. Detailed experimental laboratory data are now required to validate these simulations. While this current study has been at the laboratory scale, a simplified version of the HR model has been shown to produce reasonable simulations of two-dimensional sediment transport and deposition on the field scale (van Oost et al., 2004).

\section{REFERENCES}

Boardman, J. (2006). Soil erosion science: Reflections on the limitations of current approaches. Catena, 68,71-86.

Boesch, D., W.R. Boynton, L.B. Crowder, R.J. Diaz, R.W. Howarth, L.D. Mee, S.W. Dixon, N.N. Rabalais, R. Rosenberg, J.G. Sanders, D. Scavia and R.E. Turner. (2009). Nutrient enrichment drives Gulf of Mexico hypoxia. EOS Transactions, American Geophysical Union, 90(14), 117-119.

Cao Z., R. Day, and S. Egashira. (2002). Coupled and decoupled numerical modelling of flow and morphological evolution in alluvial rivers. Journal of Hydraulic Engineering, 128:306-321.

De Roo, A.P.J., C.G. Wesseling and C.J. Ritsema. (1996). LISEM: A single event physically-based hydrologic and soil erosion model for drainage basins: I. Theory, input and output. Hydrological Processes, 10, 1107-1117.

Diaz, R.J., and R. Rosenberg. (2008). Spreading dead zones and consequences for marine ecosystems. Science, 321, 926-929.

Eder, A., P. Strauss, T. Krueger and J.N. Quinton. (2010). Comparative calculation of suspended sediment loads with respect to hysteresis effects (in the Petzenkirchen catchment, Austria). Journal of Hydrology, 389, 168-176.

Flanagan, D.C. (2001). Preface. Proceedings of the International symposium on soil erosion research for the $21^{\text {st }}$ century, (eds., J.C. Ascough and D.C. Flanagan), 3-5 January 2001, Honolulu, Hawaii. American Society of Agricultural Engineers, St Joseph, Michigan, USA.

Flanagan, D.C. and M.A. Nearing. (1995). Water erosion prediction project: Hillslope profile and watershed documentation. NSERL Report No. 10, USDA-ARS National Soil Erosion Research laboratory, West Lafayette, Indiana, USA.

Foley, J.A., R. DeFries, G.P. Asner, C. Barford, G. Bonan, S.R. Carpenter, F.S. Chapin, M.T. Coe, G.C. Daily, H.K. Gibbs, J.H. Helkowski, T. Holloway, E.A. Howard, C.J. Kucharik, C. Monfreda, J.A. Patz, I.C. Prentice, N. Ramankutty, and P.K. Snyder. (2005). Global consequences of land use. Science, 309, 570-574.

Foster, G.R. and Meyer, L.D. (1975). Mathematical simulation of upland erosion using fundamental erosion mechanics. In Proceedings, sediment yield workshop. 28 - 30 November 1972, Report RS-S-40, pp 190 - 207, USDA Sedimentation Laboratory, Oxford Mississippi, USA.

Fowler, A.C. (1997) Mathematical models in the applied sciences. Cambridge University Press, Cambridge, England, UK.

Giménez, R., and G. Govers. (2001). Interaction between bed roughness and flow hydraulics. Water Resources Research, 37, 791-799.

Hairsine, P.B, and C.W. Rose. (1991). Rainfall detachment and deposition: Sediment transport in the absence of flow-driven processes. Soil Science Society of America Journal, 55, 320-324. 
Hairsine, P.B., and C.W. Rose. (1992). Modelling water erosion due to overland flow using physical principles, 1, Sheet flow. Water Resources Research, 28, 237-243.

Heilig, A., D. DeBruyn, M.T. Walker, C.W. Rose, J.-Y. Parlange, T.S. Steenhuis, G.C. Sander, P.B. Hairsine, W.L. Hogarth and L.P. Walker. (2001) Testing a mechanistic soil erosion model with a simple experiment. Journal of Hydrology, 244, 9-16.

Heng, B.C.P., G.C. Sander and C.F. Scott. (2009). Modelling overland flow and soil erosion on nonuniform hillslopes: A finite volume scheme. Water Resources Research, 45, W05423, doi:10.1029/2008WR007502.

Hightower, M., and S.A. Pearce. (2008). The energy challenge. Nature, 452, 285-286.

Klein, M. (1984). Anti-clockwise hysteresis in suspended sediment concentration during individual storms: Holbeck catchment, Yorkshire, England. Catena, 11, 251-257.

Lei, T., M.A. Nearing, K. Haghighi and V.F. Bralts. (1998). Rill erosion and morphological evolution: A simulation model. Water Resources Research, 34:3157-3168.

Morgan, R.P.C., and J.N. Quinton. (2001). Erosion modelling. Chapter 6, p. 117-139. In Landscape Erosion and Erosion Modelling (eds W.W. Doe and R.S. Harmon), Kluwer Academic Press, New York, USA.

Morgan, R.P.C., J.N. Quinton, R.E. Smith, G. Govers, J.W.A. Poesen, K. Auerswald, G. Chisci, D. Torri and M.E. Styczen. (1998). The European soil erosion model (EUROSEM): A dynamic approach for predicting sediment transport from fields and small catchments. Earth Surface Processes and Landforms, 23, 527-544.

Nearing, M.A., L.D. Norton, D.A. Bulgakov, G.A. Larionov, L.T. West, and K.M. Dontsova. (1997). Hydraulics and erosion in eroding rills. Water Resources Research, 33:865-876.

Oeurng, C., S. Sauvage and J. Sanchez-Perez. (2010). Dynamics of suspended sediment transport and yield in a large agricultural catchment, southwest France. Earth Surface Processes and Landforms, 35, 12891201.

Pimental, D., C. Harvey, P. Resosudarmo, K. Sinclair, D. Kurz, M. McNair, S. Crist, L. Shpritz, L. Fitton, R. Saffouri and R. Blair. (1995). Environmental and economic costs of soil erosion and conservation benefits. Science, 267,1117-1123.

Polyakov, V.O., and M.A. Nearing. (2003). Sediment transport in rill flow under deposition and detachment conditions. Catena, 51, 33-43.

Powlson, D.S., P.J. Gregory, W.R. Whalley, J.N. Quinton, D.C. Hopkins, A.P. Whitmore P.R. Hirsch and K.W.T. Goulding. (2011). Soil management in relation to sustainable agriculture and ecosystem services. Food Policy, 36, S72-S87.

Sander, G.C., J.-Y. Parlange, D.A. Barry, M.B. Parlange and W.L. Hogarth (2007). Limitation of the transport capacity approach in sediment transport modeling. Water Resources Research, 43, W02403, doi:10.1029/2006WR005177.

Sauer T., P. Hevlik, U.A. Schneider, E. Schmid, G. Kindermann and M. Obersteiner. (2010). Agriculture and resource availability in a changing world: The role of irrigation. Water Resources Research, 46 W06503, doi:10.1029/2009WR007729.

Scanlon, B.R., I. Jolly, M. Sophocleous and L. Zhang (2007). Global impacts of conversions from natural to agricultural ecosystems on water resources: Quantity versus quality. Water Resources Research, 43, W03437, doi:10.1029/2006WR005486.

Schijven, J.F., and S.M. Hassanizadeh. (2000). Removal of viruses by soil passage: Overview of modelling, processes and parameters. Critical Reviews in Environmental Science and Technology, 30, 49-127.

Seeger, M., M.P. Errea, S. Begueria, J. Arnáez, C. Marti and J. Garcia-Ruiz. (2004). Catchment soil moisture and rainfall characteristics as determinant factors for discharge/suspended sediment hysteretic loops in a small headwater catchment in the Spanish Pyrenees. Journal of Hydrology, 288, 299-311.

Smith, H.G., and D. Dragovich. (2009). Interpreting sediment delivery processes using suspended sedimentdischarge hysteresis patterns from nested upland catchments, south-eastern Australia. Hydrological Processes, 23, 2415-2426.

Smith, R.E., D.C. Goodrich, D.A. Woolhiser and C.L. Unkrich. (1995). KINEROS - A kinematic runoff and erosion model. In Singh, V.J. (Ed.), Computer models of watershed hydrology. Water Resources Publications, 697-732.

Van Oost, K., L. Beuselinck, P.B. Hairsine and G. Govers. (2004). Spatial evaluation of a multi-class sediment transport and deposition model. Earth Surface Processes and Landforms, 29, 1027-1044.

Verheijen, F.G.A., R.J.A. Jones, R.J. Rickson and C.J. Smith. (2009). Tolerable versus actual soil erosion rates in Europe. Earth-Science Reviews, 94, 23-38.

Williams, G. (1989). Sediment concentration versus water discharge during single hydrologic events in rivers. Journal of Hydrology, 111, 89-106. 